\title{
Use of capillary blood glucose for screening for gestational diabetes mellitus in resource-constrained settings
}

\author{
Balaji Bhavadharini ${ }^{1} \cdot$ Manni Mohanraj Mahalakshmi ${ }^{1} \cdot$ Kumar Maheswari $^{1}$ • \\ Gunasekaran Kalaiyarasi $^{1} \cdot$ Ranjit Mohan Anjana ${ }^{1} \cdot$ Mohan Deepa $^{1}$. \\ Harish Ranjani ${ }^{1}$ - Miranda Priya ${ }^{1}$ - Ram Uma ${ }^{2}$ Sriram Usha ${ }^{3}$ Sonak D. Pastakia ${ }^{4}$. \\ Belma Malanda $^{5}$ - Anne Belton ${ }^{5}$ Ranjit Unnikrishnan ${ }^{1} \cdot$ Arivudainambi Kayal $^{5}$. \\ Viswanathan Mohan ${ }^{1}$
}

Received: 20 January 2015/Accepted: 12 April 2015/Published online: 28 April 2015

(C) The Author(s) 2015. This article is published with open access at Springerlink.com

\begin{abstract}
Aims The aim of the study was to evaluate usefulness of capillary blood glucose (CBG) for diagnosis of gestational diabetes mellitus (GDM) in resource-constrained settings where venous plasma glucose (VPG) estimations may be impossible.

Methods Consecutive pregnant women $(n=1031)$ attending antenatal clinics in southern India underwent $75-\mathrm{g}$ oral glucose tolerance test (OGTT). Fasting, 1- and 2-h VPG (AU2700 Beckman, Fullerton, CA) and CBG (One Touch Ultra-II, LifeScan) were simultaneously measured. Sensitivity and specificity were estimated for different CBG cut points using the International Association of Diabetes in Pregnancy Study Groups (IADPSG) criteria for the diagnosis of GDM as gold standard. Bland-Altman
\end{abstract}

Managed by Massimo Federici.

Electronic supplementary material The online version of this article (doi:10.1007/s00592-015-0761-9) contains supplementary material, which is available to authorized users.

Viswanathan Mohan

drmohans@diabetes.ind.in;

http://www.drmohansdiabetes.com; http://www.mdrf.in

1 Madras Diabetes Research Foundation and Dr. Mohan's Diabetes Specialities Centre, WHO Collaborating Centre for Non-communicable Diseases Prevention and Control, IDF Centre of Education, 4, Conran Smith Road, Gopalapuram, Chennai 600 086, India

2 Seethapathy Clinic and Hospital, Chennai, India

3 Associates in Clinical Endocrinology Education and Research (ACEER), Chennai, India

4 College of Pharmacy, Purdue University, West Lafayette, IN, USA

5 International Diabetes Federation, Brussels, Belgium plots were drawn to look at the agreement between CBG and VPG. Correlation and regression equation analysis were also derived for CBG values.

Results Pearson's correlation between VPG and CBG for fasting was $r=0.433$ [intraclass correlation coefficient $(\mathrm{ICC})=0.596, p<0.001]$, for $1 \mathrm{H}$, it was $r=0.653$ $(\mathrm{ICC}=0.776, \quad p<0.001), \quad$ and for $2 \mathrm{H}, \quad r=0.784$ $(\mathrm{ICC}=0.834, p<0.001)$. Comparing a single CBG 2-h cut point of $140 \mathrm{mg} / \mathrm{dl}(7.8 \mathrm{mmol} / \mathrm{l})$ with the IADPSG criteria, the sensitivity and specificity were 62.3 and $80.7 \%$, respectively. If $\mathrm{CBG}$ cut points of $120 \mathrm{mg} / \mathrm{dl}$ $(6.6 \mathrm{mmol} / \mathrm{l})$ or $110 \mathrm{mg} / \mathrm{dl}(6.1 \mathrm{mmol} / \mathrm{l})$ were used, the sensitivity improves to 78.3 and $92.5 \%$, respectively.

Conclusions In settings where VPG estimations are not possible, $\mathrm{CBG}$ can be used as an initial screening test for GDM, using lower $2 \mathrm{H} \mathrm{CBG}$ cut points to maximize the sensitivity. Those who screen positive can be referred to higher centers for definitive testing, using VPG.

Keywords Gestational diabetes mellitus - Capillary blood glucose - Venous plasma glucose $\cdot \mathrm{CBG} \cdot \mathrm{WHO}$ 1999 criteria $\cdot$ IADPSG criteria $\cdot$ Screening $\cdot$ Asian Indian . South Asians

\section{Introduction}

The prevalence of gestational diabetes mellitus (GDM) is rapidly increasing and currently affects up to $15 \%$ of pregnant women worldwide [1]. In India, in 2011, 62.4 million people were reported to have diabetes [2], while 4 million women were reported to have GDM [3].

Screening and diagnosis of GDM has been a matter of intense debate. The oral glucose tolerance test (OGTT) remains the gold standard for diagnosis of GDM. Based on 
the Hyperglycemia and Adverse Pregnancy Outcome (HAPO) study [4], the International Association of Diabetes in Pregnancy Study Groups (IADPSG) criteria were developed which recommends three venous plasma glucose samples, i.e., fasting, one and $2 \mathrm{~h}$ after administration of $75 \mathrm{~g}$ glucose [5]. However, in many resource-constrained settings in the developing world, obtaining venous samples may be difficult or indeed impossible, due to shortage of trained phlebotomists and limited access to standardized laboratories. In such situations, if screening for GDM is to be done at all, the only alternative would be to use a handheld blood glucose meter to perform capillary blood glucose (CBG) testing. Currently, the use of CBG for diagnosis of GDM is not recommended. There are few studies comparing CBG with the old WHO 1999 criteria for GDM [6] but none, to our knowledge, have compared CBG with IADPSG criteria.

The objectives of this paper, therefore, were as follows:

1. To compare capillary blood glucose (CBG) estimation using a handheld glucose meter with the venous plasma glucose (VPG) estimation using the IADPSG criteria as the gold standard, for diagnosis of GDM.

2. To derive regression equations for the VPG fasting, 1and 2-h values from the corresponding CBG estimations and

3. To see whether CBG can at least be used as an initial screening test before referring patients to higher centers for a diagnostic OGTT using VPG.

\section{Methods}

This study is a part of an ongoing program called Women in India with GDM Strategy (WINGS) conducted under the auspices of the International Diabetes Federation (IDF) [7]. One of the aims of the WINGS program was to identify the best strategy which could be widely applied in resourceconstrained settings for screening of women with GDM. This paper deals with the results of the screening study, using CBG and VPG carried out between January and November 2013.

\section{Ethical clearance}

All participants gave written informed consent prior to participating in the study. All procedures followed were in accordance with the ethical standards and in keeping with the Helsinki Declaration of 1975, as revised in 2008. Permission was obtained from the Director of Public Health and the Health Secretary, Government of Tamil Nadu to undertake the WINGS program. The study proposal was approved by the Institutional Ethics Committee of the Madras Diabetes Research Foundation, Chennai, India.

\section{Study sites}

Nine urban health centers in Chennai city and 11 rural centers in Kanchipuram district, from Tamil Nadu state in southern India, were selected for this study.

\section{Pilot screening method}

All participants gave written informed consent to participate in the study. For all participants, an intervieweradministered case report form was used to obtain demographic information including age and period of gestation (weeks), along with general medical history and family history of diabetes. Anthropometric measurements were done using standard techniques. Height was measured using a stadiometer (SECA Model 213, Seca Gmbh Co, Hamburg, Germany) to the nearest $0.1 \mathrm{~cm}$, and weight was measured with an electronic weighing machine (SECA Model 803, Seca Gmbh Co) to the nearest $0.1 \mathrm{~kg}$. The body mass index (BMI) was calculated using the formula weight (in $\mathrm{kg}$ ) divided by height in meters (squared) [8]. All participants underwent a 75-g oral glucose tolerance test (OGTT) in the fasting state, i.e., after at least $8 \mathrm{~h}$ of no caloric intake. Venous plasma glucose (VPG) and capillary blood glucose (CBG) were measured simultaneously (within 1-2 min of each other).

Blood samples were collected in sodium fluoride/ $\mathrm{Na} 2$ EDTA Vacutainer tubes to prevent glycolysis. Samples were transported to the central laboratory within $1-2 \mathrm{~h}$ in cool boxes which had gel packs to maintain the temperature between 2 and $8{ }^{\circ} \mathrm{C}$.

Fasting, 1-h $(1 \mathrm{H})$ and 2-h $(2 \mathrm{H})$ samples were drawn from the antecubital vein, and VPG was measured in our laboratory using an autoanalyzer (AU2700 Beckman, Fullerton, CA). Capillary blood samples were also simultaneously drawn at fasting, 1 and $2 \mathrm{~h}$ from a finger stick blood sample, and CBG was measured using a handheld glucose meter (One Touch Ultra-II, LifeScan, Johnson \& Johnson, Milpitas, CA). The glucose meter used is plasma calibrated, and without hematocrit correction, it provides accurate results for a hematocrit range of 30-50\%.The intra- and inter-assay coefficients of variation (CV) for the venous blood glucose ranged from 0.78 to $1.68 \%$, while the mean coefficient of variation for $\mathrm{CBG}$ was $4.2 \%$. Hemoglobin was measured using SLS (sodium lauryl sulfate)-hemoglobin method.

\section{Definitions of GDM}

1. Using VPG: According to the IADPSG criteria [5], GDM was diagnosed based on any one of the following VPG values obtained in the OGTT: 
fasting $\geq 92 \mathrm{mg} / \mathrm{dl} \quad(5.1 \mathrm{mmol} / \mathrm{l}), \quad 1 \mathrm{~h} \geq 180 \mathrm{mg} / \mathrm{dl}$ $(9.9 \mathrm{mmol} / \mathrm{l})$ or $2 \mathrm{~h} \geq 153 \mathrm{mg} / \mathrm{dl}(8.4 \mathrm{mmol} / \mathrm{l})$.

2. Using CBG: There are no defined cut points for $\mathrm{CBG}$ in pregnancy. To compare with the IADPSG criteria, we used the same CBG cut points as IADPSG criteria VPG values given above. In non-pregnant adults, the World Health Organization (WHO) recommends using $20 \mathrm{mg} / \mathrm{dl}$ higher values for post-glucose load CBG estimations [9]. Hence, additionally, we also used $20 \mathrm{mg} / \mathrm{dl}(1.1 \mathrm{mmol} / \mathrm{l})$ higher CBG cut points for the 1 - and 2-h values [i.e., $200 \mathrm{mg} / \mathrm{dl}(11.1 \mathrm{mmol} / \mathrm{l})$ and $173 \mathrm{mg} / \mathrm{dl}(9.6 \mathrm{mmol} / \mathrm{l})]$.

\section{Statistical analysis}

Statistical analyses were performed using SPSS for Windows version 20 (SPSS Inc., Chicago, IL). Sensitivity, specificity, positive predictive value, negative predictive value and accuracy of different CBG cut points were calculated for the IADPSG criteria using MedCalc version 12.7.0. Bland-Altman plots were drawn to look at the agreement between CBG and VPG in fasting, $1 \mathrm{H}$ and $2 \mathrm{H}$ samples and to see whether it was within the $95 \%$ limits. Pearson's correlation was used to compare CBG and VPG values at fasting, $1 \mathrm{H}$ and $2 \mathrm{H}$ time points. Regression equations were derived for VPG values at fasting, $1 \mathrm{H}$ and $2 \mathrm{H}$ using the CBG estimations.

\section{Results}

The mean age of the 1031 women was $23.9 \pm 3$ years; mean BMI, $22.5 \pm 3.9 \mathrm{~kg} / \mathrm{m}^{2}$; mean period of gestation, $23.6 \pm 7.6$ weeks; and mean hemoglobin, $11.2 \pm 3.8 \mathrm{gm} /$ dl.

The Pearson's correlation between VPG and CBG in the fasting state was $r=0.433$ [intraclass correlation coefficient $(\mathrm{ICC})=0.596, p<0.001]$, for $1 \mathrm{H}$, it was $r=0.653$ (ICC $=0.776, p<0.001$ ), and for $2 \mathrm{H}$, it was $r=0.784$ $(\mathrm{ICC}=0.834, p<0.001)$.

To derive the VPG from the CBG values, the regression equations were fasting $\mathrm{VPG}=51.02+0.36 \times$ fasting $\mathrm{CBG} ; 1$-h $\mathrm{VPG}=48.91+0.52 \times 1-\mathrm{h} \quad \mathrm{CBG}$ and $2-\mathrm{h}$ $\mathrm{VPG}=33.21+0.59 \times 2-\mathrm{h}$ CBG.

Bland-Altman plots were drawn to study the limits of agreement between VPG and CBG for fasting, $1 \mathrm{H}$ and $2 \mathrm{H}$ cut points (Fig. 1a-c). The mean difference for fasting, $1 \mathrm{H}$ and $2 \mathrm{H}$ was $0.5,17.2$ and $19.7 \mathrm{mg} / \mathrm{dl}$, respectively, and their $1.96 \mathrm{SD}$ ranged from -20.7 to $21.7 \mathrm{mg} / \mathrm{dl},-19.3$ to $53.7 \mathrm{mg} / \mathrm{dl}$ and -27.6 to $67 \mathrm{mg} / \mathrm{dl}$, respectively.

Figure $2 \mathrm{a}$ shows the comparison between the IADPSG criteria and the same $\mathrm{CBG}$ cut points, i.e., fasting $\geq 92 \mathrm{mg} / \mathrm{dl}$ or $1 \mathrm{~h} \geq 180 \mathrm{mg} / \mathrm{dl}$ or $2 \mathrm{~h} \geq 153 \mathrm{mg} / \mathrm{dl}$. Out of the 106 GDM women picked up by the IADPSG VPG criteria, CBG identified 83 (78.3\%). However, additionally 228 women who did not have GDM by IADPSG VPG criteria were identified as having GDM by CBG.

Figure $2 b$ shows the comparison between the IADPSG criteria and the $20 \mathrm{mg} / \mathrm{dl}$ higher $\mathrm{CBG}$ cut points for the post-stimulated state, i.e., fasting $\geq 92 \mathrm{mg} / \mathrm{dl}$ or $1 \mathrm{~h} \geq 200 \mathrm{mg} / \mathrm{dl}$ or $2 \mathrm{~h} \geq 173 \mathrm{mg} / \mathrm{dl}$. Out of the 106 GDM women picked up by the IADPSG criteria, CBG identified 73 women (68.9\%). However, 128 women who did not have GDM by IADPSG criteria were identified as having GDM by $\mathrm{CBG}$.

With the idea of maximizing the sensitivity of a single $2 \mathrm{H} \mathrm{CBG}$ value, if used as an initial screening tool for GDM, we next constructed receiver operating curves with different $2 \mathrm{H} \mathrm{CBG}$ cut points and compared the sensitivity, specificity, positive predictive value, negative predictive value and accuracy of these cut points using the IADPSG criteria as the gold standard, and the data are presented in Table 1.

A $2 \mathrm{H} \mathrm{CBG}$ cut point of $126 \mathrm{mg} / \mathrm{dl}(7.0 \mathrm{mmol} / \mathrm{l})$ gave the optimum sensitivity and specificity of 70.8 and $63 \%$, respectively, with a C statistic (AUC) of 0.778 (95\% confidence interval, CI 0.726-0.829). If the cut point is lowered to $120 \mathrm{mg} / \mathrm{dl}(6.6 \mathrm{mmol} / \mathrm{l})$, the sensitivity improved to $78.3 \%$, and if lowered to $110 \mathrm{md} / \mathrm{dl}(6.1 \mathrm{mmol} /$ 1), it improved to $92.5 \%$. However, 50.1 and $68.9 \%$ of women, respectively, have to be referred for the definitive diagnostic OGTT using VPG.

Supplemental Table 1 presents the sensitivity and specificity of the fasting capillary blood glucose (fasting $\mathrm{CBG}$ ) in comparing to the IADPSG. It can be seen that a fasting $\mathrm{CBG}$ cut point of $80 \mathrm{mg} / \mathrm{dl}(4.4 \mathrm{mmol} / \mathrm{l})$ gave the optimum sensitivity and specificity of 67.9 and $58.5 \%$, respectively, with a $\mathrm{C}$ statistic (AUC) of 0.727 (95\% confidence interval, CI 0.673-0.780). For lower cut points of 75 and $70 \mathrm{mg} / \mathrm{dl}$, the sensitivity was 79.3 and $92.5 \%$, but the corresponding specificity was 36.9 and $16.1 \%$, respectively. Thus, it is clear that the sensitivity and specificity of the fasting CBG is not satisfactory.

\section{Discussion}

There is considerable controversy regarding the best screening and diagnostic test for diagnosis of GDM. Based on the Hyperglycemia and Adverse Pregnancy Outcomes (HAPO) study, the IADPSG guidelines were introduced in an attempt to reach a global consensus for the diagnosis of GDM [5]. The WHO has recently approved the IADPSG criteria [10], effectively replacing the original WHO 1999 criteria [11] with the IADPSG criteria. However, the WHO 

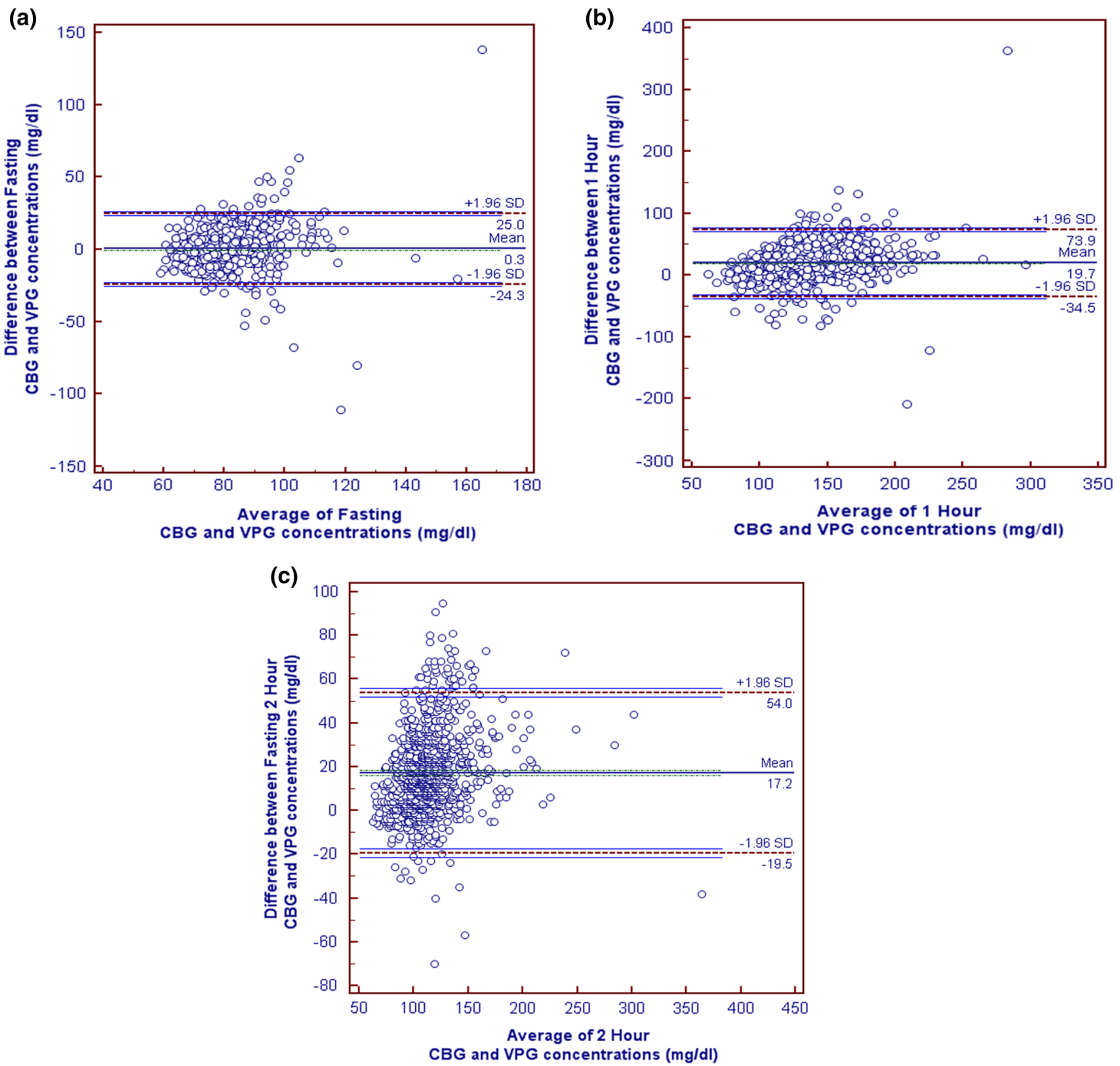

Fig. 1 Bland and Altman plots. a Fasting CBG and VPG values, b $1 \mathrm{H} \mathrm{CBG}$ and VPG values, c 2H CBG and VPG values

1999 criteria which require only one blood sample $(2 \mathrm{~h}$ after a $75 \mathrm{~g}$ glucose load) are quite widely used in India and other developing countries and even in many developed countries like the UK, because of its simplicity [12]. Nevertheless, both the IADPSG and the WHO 1999 criteria require venous plasma samples which are often a challenge in resource-constrained settings in developing countries.

This paper looks at an alternative method of screening for GDM in resource-constrained settings by means of a handheld glucose meter using CBG. The advantage of using CBG is that even lay people can be trained to do the screening as it serves as a portable, point of care and cost- effective tool for screening. Moreover, obtaining a finger prick sample is minimally invasive when compared with venous blood draw and hence more acceptable to the subjects [13].

Earlier, glucose meters were exclusively used for home glucose monitoring by people with diabetes, but they are gaining acceptance as a screening tool in large epidemiological studies in developing countries such as India due to logistic difficulties in getting venous blood samples due to lack of phlebotomists and lack of standardized laboratories especially in rural areas where $72 \%$ of the population lives $[2,14]$. 

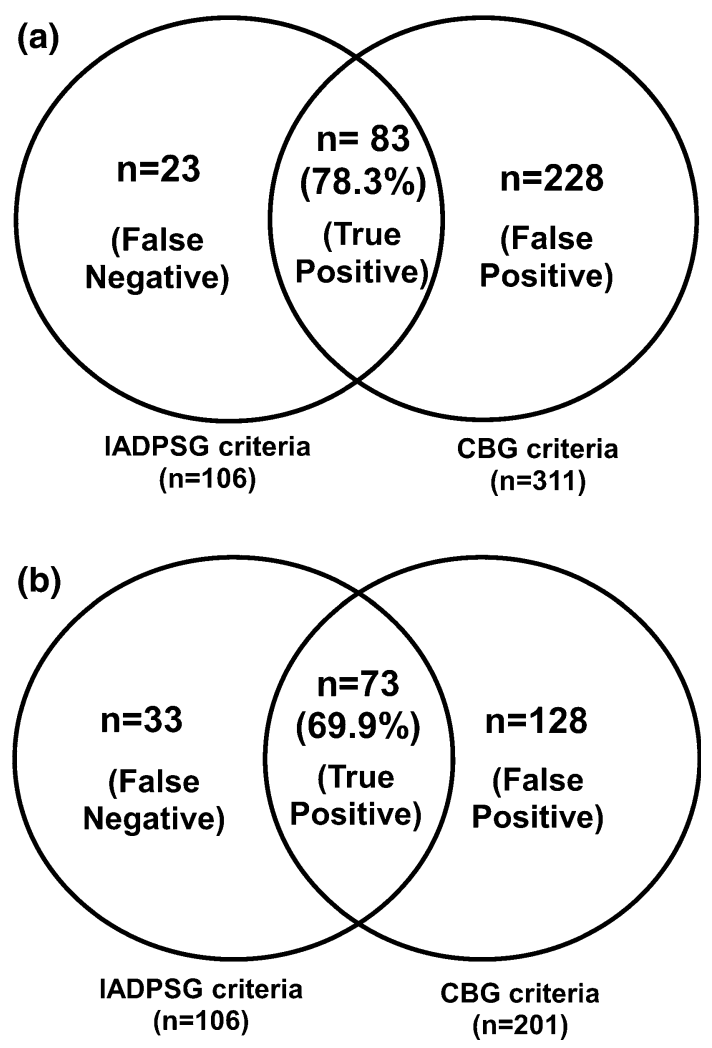

Fig. 2 a Comparison of diagnosis of GDM by the IADPSG criteria and CBG cut point of Fasting $\geq 92 \mathrm{mg} / \mathrm{dl}$ or $1 \mathrm{~h} \geq 180 \mathrm{mg} / \mathrm{dl}$ or $2 \mathrm{~h} \geq 153 \mathrm{mg} / \mathrm{dl}$, $\mathbf{b}$ comparison of diagnosis of GDM by the IADPSG criteria and CBG cut point of Fasting $\geq 92 \mathrm{mg} / \mathrm{dl}$ or $1 \mathrm{~h} \geq 200 \mathrm{mg} /$ $\mathrm{dl}$ or $2 \mathrm{~h} \geq 173 \mathrm{mg} / \mathrm{dl}$

For non-pregnant adults, the WHO has suggested use of the same cut points for CBG as for VPG for diagnosis of diabetes in the fasting state but to use $20 \mathrm{mg} / \mathrm{dl}(1.1 \mathrm{mmol} /$ 1) higher cut points for the $2 \mathrm{~h}$ post-glucose value in OGTT [10]. Unfortunately, no such guidelines exist for use of CBG during pregnancy, i.e., for diagnosis of GDM. Hence, we used 2 cut points, a CBG $2 \mathrm{H}$ cut point of $140 \mathrm{mg} / \mathrm{dl}$ ( $7.8 \mathrm{mmol} / \mathrm{l}$ ) which is the $2 \mathrm{H} \mathrm{VPG}$ cut point for the old
WHO 1999 criteria for GDM [11] as well as the $160 \mathrm{mg} / \mathrm{dl}$ ( $8.9 \mathrm{mmol} / \mathrm{l}) 2 \mathrm{H} \mathrm{CBG}$ cut point. In addition, we also used the same CBG cut points as the fasting, $1 \mathrm{H}$ and $2 \mathrm{H} \mathrm{VPG}$ IADPSG criteria and also the $20 \mathrm{mg} / \mathrm{dl}$ higher cut points for the $1 \mathrm{H}$ and $2 \mathrm{H} \mathrm{CBG}$ values following the WHO recommendations of using $20 \mathrm{mg} / \mathrm{dl}$ higher cut points in the non-pregnant state for the stimulated glucose values. We have also derived regression equations for venous plasma glucose in the fasting, 1- and 2-h samples using CBG which can help in calculating the approximate VPG values from $\mathrm{CBG}$ measurements.

We found that if we use the same CBG cut points as the IADPSG criteria, 23 women $(21.7 \%)$ would be missed, while 33 women $(31.1 \%)$ would be missed if CBG cut points of fasting $\geq 92 \mathrm{mg} / \mathrm{dl}$ or $1 \mathrm{~h} \geq 200 \mathrm{mg} / \mathrm{dl}$ or $2 \mathrm{~h} \geq 173 \mathrm{mg} / \mathrm{dl}$ is used. Moreover, there are a significant number of false positives. So, it is clear that CBG cannot be used for diagnosis of GDM but perhaps can be used as an initial screening test in resource-constrained settings.

Dillon et al. [15] report that CBG values are higher when compared to venous sample due to slow metabolization of glucose in peripheral tissues. Several factors influence the CBG measurements performed by different methods [16-18]. Arterial blood shows higher glucose values than venous blood. The difference may be due to the balance between the water and glucose in the analyzed blood [19] and also due to different glucose meters used in various studies. Factors such as environmental exposure (e.g., moisture, altitude) can affect the accuracy of glucose meter results. Therefore, adequate training should be imparted to the field staff to perform the CBG test correctly. Clinical differences may also alter the accuracy of glucose meters. Conditions affecting blood, such as anemia, have also been documented to alter the settings where such conditions are found to have a higher prevalence. However, there was no difference in the prevalence of anemia between the GDM and the non-GDM women. Hence, this is unlikely to have affected the results of this study.

Table 1 Comparison of sensitivity and specificity of different 2H CBG levels for the diagnosis of GDM using the IADPSG criteria as the gold standard

\begin{tabular}{lllllll}
\hline $\begin{array}{l}\text { 2H CBG cut point } \\
(\mathrm{mg} / \mathrm{dl})\end{array}$ & Sensitivity $(\%)$ & Specificity $(\%)$ & PPV (\%) & NPV (\%) & Accuracy (\%) & $\begin{array}{l}\text { \% of population who have } \\
\text { levels above this value }\end{array}$ \\
\hline $100(5.5 \mathrm{mmol} / \mathrm{l})$ & 96.2 & 18.8 & 12.0 & 97.8 & 82.9 & 82.7 \\
$110(6.1 \mathrm{mmol} / \mathrm{l})$ & 92.5 & 33.7 & 13.8 & 97.5 & 74.2 & 68.9 \\
$120(6.6 \mathrm{mmol} / \mathrm{l})$ & 78.3 & 53.1 & 16.1 & 95.5 & 65.7 & 50.1 \\
$126(7.0 \mathrm{mmol} / \mathrm{l})$ & 70.8 & 63.0 & 18.0 & 95.0 & 66.2 & 40.4 \\
$130(7.2 \mathrm{mmol} / \mathrm{l})$ & 67.0 & 68.7 & 19.7 & 94.8 & 68.1 & 35.0 \\
$140(7.7 \mathrm{mmol} / \mathrm{l})$ & 62.3 & 80.7 & 26.3 & 94.9 & 76.3 & 23.7 \\
$150(8.3 \mathrm{mmol} / \mathrm{l})$ & 51.9 & 88.4 & 34.0 & 94.1 & 82.7 & 15.7 \\
$160(8.8 \mathrm{mmol} / \mathrm{l})$ & 40.0 & 93.9 & 48.6 & 91.6 & 88.3 & 10.3 \\
\hline
\end{tabular}


Based on our results, we conclude that VPG would still need to be used as the diagnostic test for GDM. The sensitivity and specificity of the fasting CBG are not acceptable. However, perhaps the $2 \mathrm{H} \mathrm{CBG}$ test could be used as an initial screening test in field settings in remote areas where getting venous samples is impossible. All those with values above a certain cut point could be referred to a higher center for a diagnostic OGTT using VPG. Admittedly, the sensitivity for diagnosing GDM using the IADPSG criteria is still not optimum. This is largely because the IADPSG criteria include a fairly low fasting plasma glucose (FPG) cut point of $92 \mathrm{mg} / \mathrm{dl}(5.1 \mathrm{mmol} / \mathrm{l})$. If a $2 \mathrm{H} \mathrm{CBG}$ cut point of $120 \mathrm{mg} / \mathrm{dl}(6.6 \mathrm{mmol} / \mathrm{l})$ or $110 \mathrm{mg} / \mathrm{dl}(6.1 \mathrm{mmol} / \mathrm{l})$ was used as an initial screening test, the sensitivity improves to 78.3 and $92.5 \%$, respectively. However, 50.1 and $68.9 \%$ of women would have to be referred to higher centers for the diagnostic OGTT.

While there are little data on the comparative costs of VPG and CBG, one study suggests that doing CBG could help reduce the cost by $80 \%$ compared to VPG done in a laboratory [20]. This could be because of cost of Vacutainers or blood collection tubes, syringes, transportation cost, salaries of laboratory personnel, use of auto analyzers or other laboratory equipments and reagents can be avoided.

Moreover, doing a $2 \mathrm{H} \mathrm{CBG}$ as an initial screening test might prove to be cost-effective since only a fraction of women would have to be referred for the diagnostic OGTT. Furthermore, even if it is not cost- effective, this may be the only option available in resource-constrained settings where VPG cannot be done. Having said this, proper cost-effective studies need to be done which is one of the limitations of this study. Also, the reliability of glucose meter can be influenced by several environmental factors like humidity. Nevertheless, rigorous training for technicians and continuous quality control measures ensured accuracy of the results. The strength of the study is that it has a fairly large sample size and has systematically compared CBG with the IADPSG criteria which was taken as the gold standard.

In summary, for screening and diagnosing GDM, the VPG still remains the gold standard. However, in resource-constrained situations in developing countries where obtaining venous samples is impossible, the initial screening can be done by CBG using handheld glucose meters with lower $2 \mathrm{H}$ glucose cut points (the actual cut points used depending on the resources available) to maximize the sensitivity. Those who screen positive can be referred to higher centers for the definitive diagnostic test using VPG where the gold standard test would be the IADPSG criteria, as it is now being widely accepted worldwide $[11,21]$.
Acknowledgments $\mathrm{We}$ are grateful to the International Diabetes Federation (IDF) and Abbott Fund for their support for the WINGS program. We would also like to place on record our sincere thanks to the Director of Public Health and the Health Secretary, the Government of Tamil Nadu for giving us the permission to carry out the WINGS program. We also thank the village health nurses and the doctors and study participants for their support. This is the second publication from the WINGS program (WINGS-2).

Conflict of interest Balaji Bhavadharini, Manni Mohanraj Mahalakshmi, Kumar Maheswari, Gunasekaran Kalaiyarasi, Ranjit Mohan Anjana, Mohan Deepa, Harish Ranjani, Miranda Priya, Ram Uma, Sriram Usha, Sonak D. Pastakia, Belma Malanda, Anne Belton, Ranjit Unnikrishnan, Arivudainambi Kayal and Viswanathan Mohan declare that they have no conflict of interest.

Ethical standard All procedures performed in studies involving human participants were in accordance with the ethical standards of the institutional and/or national research committee and with the 1964 Helsinki Declaration and its later amendments or comparable ethical standards.

Human and animal rights All human rights were observed in keeping with Declaration of Helsinki 2008 (ICH GCP) and the Indian Council of Medical Research (ICMR) guidelines. There are no animal rights issues as this is a clinical study.

Informed consent Informed consent was obtained from all patients for being included in the study which has been done according to the ethical standards and in keeping with Helsinki Declaration of 2008 (ICH GCP).

Open Access This article is distributed under the terms of the Creative Commons Attribution 4.0 International License (http://creativecommons.org/licenses/by/4.0/), which permits unrestricted use, distribution, and reproduction in any medium, provided you give appropriate credit to the original author(s) and the source, provide a link to the Creative Commons license, and indicate if changes were made.

\section{References}

1. International Diabetes Federation (2013) Policy briefing. Diabetes in pregnancy: protecting maternal health. IDF. Brussels. http://www.idf.org/sites/default/files/Policy_Briefing_DiabetesIn Pregancy.pdf. Accessed 12 Jan 2015

2. Anjana RM, Pradeepa R, Deepa M, Datta M, Sudha V, Unnikrishnan R, On behalf of the ICMR-INDIAB Collaborative Study Group et al (2011) Prevalence of diabetes and prediabetes (impaired fasting glucose and/or impaired glucose tolerance) in urban and rural India: phase I results of the Indian Council of Medical research-India Diabetes (ICMR-INDIAB) study. Diabetologia 54:3022-3027

3. International Diabetes Federation (IDF) (2013) Website. http:// www.idf.org/node/26045. Accessed 12 Sept 2014

4. Coustan DR, Lowe LP, Metzger BE, Dyer AR, International Association of Diabetes and Pregnancy Study Groups (2010) The hyperglycemia and adverse pregnancy outcome (HAPO) study: paving the way for new diagnostic criteria for gestational diabetes mellitus. Am J Obstet Gynecol 202:654.e1-654.e6

5. International Association of Diabetes and Pregnancy Study Groups (2010) International Association of Diabetes and Pregnancy Study Groups recommendations on the diagnosis and 
classification of hyperglycemia in pregnancy. Diabetes Care 33:676-682

6. Balaji V, Madhuri BS, Paneerselvam A, Arthi T, Seshiah V (2012) Comparison of venous plasma glucose and capillary whole blood glucose in the diagnosis of gestational diabetes mellitus: a community-based study. Diabetes Technol Ther 14:131-134

7. Women in India with GDM strategy (WINGS) (2015) http:// www.idf.org/women-india-gdm-strategy-wings. Accessed 12 Jan 2015

8. Deepa M, Pradeepa R, Rema M, Mohan A, Deepa R, Shanthirani S, Mohan V (2003) The Chennai Urban Rural Epidemiology Study (CURES) — study design and methodology (urban component) (CURES-1). J Assoc Physicians India 51:863-870

9. World Health Organization (2006) Definition and diagnosis of diabetes mellitus and intermediate hyperglycemia: report of a WHO/IDF consultation. World Health Organization, Geneva, p 39

10. Diagnostic criteria and classification of hyperglycemia first detected in pregnancy. World Health Organization 2013, p 63; WHO/NMH/MND/13.2

11. Definition, diagnosis and classification of diabetes mellitus and its complications report of a WHO consultation part 1: diagnosis and classification of diabetes mellitus 1999

12. Schmidt MI, Duncan BB, Reichelt AJ, Branchtein L, Matos MC, Costa e Forti A A, Brazilian Gestational Diabetes Study Group et al (2001) Gestational diabetes mellitus diagnosed with a 2-h $75 \mathrm{~g}$ oral glucose tolerance test and adverse pregnancy outcomes. Diabetes Care 24(7):1151-1155
13. Weiss PAM, Haeusler MCH, Kainer F, Purstner P, Haas J (1998) Towards universal criteria for gestational diabetes: relationships between 75 and $100 \mathrm{~g}$ glucose loads and between capillary and venous glucose concentrations. Am J Obstet Gynecol 178: 830-835

14. Priya M, Anjana RM, Pradeepa R et al (2011) Comparison of capillary whole blood versus venous plasma glucose estimations in screening for diabetes mellitus in epidemiological studies in developing countries. Diabetes Technol Ther 13:586-591

15. Dillon AE, Menard MK, Rust P, Newman RB, VanDorsten JP (1997) Glucometer analysis of one-hour glucose challenge samples. Am J Obstet Gynecol 177:1120-1123

16. Gautier JF, Bigard AX, Douce P, Duvallet A, Cathelineau G (1996) Influence of simulated altitude on the performance of five blood glucose meters. Diabetes Care 19:1430-1433

17. Lunt H, Florkowski C, Bignall M, Budgen C (2010) Capillary glucose meter accuracy and sources of error in the ambulatory setting. N Z Med J 123:74-85

18. Tonyushkina K, Nichols JH (2009) Glucose meters: a review of technical challenges to obtaining accurate results. J Diabetes Sci Technol 3:971-980

19. Blake DR, Nathan DM (2004) Point-of-care testing for diabetes. Crit Care Nurs Q 27:150-161

20. Meriggi E, Trossarelli GF, Carta Q, Menato G, Porta MA, Bordon R, Gagliardi L (1988) Capillary glucose determination in the screening of gestational diabetes. Diabetes Res Clin Pract 5:55-61

21. American Diabetes Association (2013) Standards of Medical Care in Diabetes-2013. Diabetes Care 36:S67-S74 